\title{
Management of acute bacterial skin and skin structure infections in India: are we equipped to meet the challenges of the growing menace of methicillin-resistant Staphylococcus aureus?
}

\section{Chandrashekhar Mahakalkar'1, Devdatta Padhye², Vishal R. Nandagawali³, Shekhar Takale ${ }^{4}$, Jaishid Ahdal ${ }^{5 *}$, Rishi Jain ${ }^{5}$}

\author{
${ }^{1}$ Department of Surgery, Datta Meghe Institute of Medical Sciences, Jawaharlal Nehru Medical College, Wardha, \\ Maharashtra, India \\ ${ }^{2}$ Department of Surgery, Life point multi-speciality hospital, Pune, Maharashtra, India \\ ${ }^{3}$ Department of Surgery, Indira Gandhi Government Medical College and Hospital, Nagpur, Maharashtra, India \\ ${ }^{4}$ Department of Surgery, Oyster and Pearl Hospital, Pune, Maharashtra, India \\ ${ }^{5}$ Department of Medical Affairs, Wockhardt Limited, Mumbai, Maharashtra, India
}

Received: 02 June 2020

Revised: 07 July 2020

Accepted: 16 July 2020

\section{*Correspondence: \\ Dr. Jaishid Ahdal, \\ E-mail: jahdal@wockhardt.com}

Copyright: (C) the author(s), publisher and licensee Medip Academy. This is an open-access article distributed under the terms of the Creative Commons Attribution Non-Commercial License, which permits unrestricted non-commercial use, distribution, and reproduction in any medium, provided the original work is properly cited.

\begin{abstract}
Staphylococcus aureus (S. aureus) is a Gram-positive facultative anaerobic bacterium that colonizes the skin and nasal passages of humans. The incidence of invasive $S$. aureus infections has increased over the past decades and is associated with poor outcomes and high mortality rates. S. aureus is responsible for almost one-third of acute bacterial skin and skin structure infections with methicillin-resistant Staphylococcus aureus (MRSA) accounting for a large proportion of these. The $S$. aureus strains prevalent in India are more aggressive and there are recent reports of the emergence of the more virulent multidrug resistant lineages ST2371 and ST8. Management of these infections is complicated by the fact that antimicrobial stewardship is non-existent, the choice of treatment is often empirical and available treatment options are limited due to a high prevalence of resistance strains. Currently available anti-MRSA agents include vancomycin, teicoplanin, linezolid, daptomycin, tigecycline, and clindamycin. However, the emergence of resistant strains and several undesirable features related to the safety and tolerability of these agents have limited the options available for the management of MRSA infections. A newer, safe and efficacious antibiotic is thus an unmet need for the management of MRSA in patients with acute bacterial skin and skin structure infections. In this review we explore the current and future trends in the management of acute bacterial skin and skin structure infections highlighting the challenges in their management in India, and current progress in the development of some novel drugs for the management of MRSA infections.
\end{abstract}

Keywords: Acute bacterial skin and skin structure infections, Methicillin-resistant Staphylococcus aureus, AntiMRSA agents, Multi-drug resistance

\section{INTRODUCTION}

Staphylococcus (MSSA) and aureus, both methicillin-sensitive methicillin-resistant (MRSA) are responsible for causing a range of mild to life-threatening infections such as skin and soft-tissue infections (SSTIs), osteomyelitis and endocarditis. Staphylococcus aureus is the most common organism isolated in primary and 
secondary skin infections. These are usually treated with penicillin and its derivatives but increasing resistance in MRSA has led to a renewed focus on other antibiotics. ${ }^{1}$ We reviewed the burden of MRSA focusing on the challenges in the treatment of SSTIs in India. We also reviewed some novel drugs that are under development.

\section{REVIEW OF LITERATURE}

\section{MRSA and the types of wounds}

S. aureus is commonly isolated from skin and soft-tissue infections such as impetigo, wounds, furuncles, burns, abscesses and systemic infections especially those of the respiratory and urinary tracts. It has a predilection for the immunosuppressed and those with severe burn wounds. Both superficial infections and severe sepsis are frequently seen in healthcare centres and hospitals, most often in maternity wards where they can cause severe sepsis in babies, abscesses in nursing mothers, and carbuncles in the staff. $S$. aureus infections are also commonly associated with surgical wounds, catheters, implanted feeding tubes or other invasive devices. ${ }^{2}$

\section{Epidemiology of MRSA in acute bacterial skin and skin structure infections}

In the United States, SSTIs account for $\sim 10 \%$ of hospital admissions for all infections, of which the majority are MRSA. ${ }^{1}$ The increasing number of outbreaks of SSTI around the world results in significant morbidity and mortality along with high direct and indirect costs. ${ }^{3}$ Globally, MRSA accounts for a considerable proportion of acute bacterial skin and soft-tissue structure infections and it is now a serious public health issue all over the world with high endemicity in various Western and Asian countries. Both hospital-acquired (HA-MRSA) and community-acquired MRSA (CA-MRSA) have caused epidemics of SSTIs leading to considerable morbidity and mortality since the 1990s. ${ }^{4}$ Although MRSA infections have been reported in India since the 1980s, it has only recently been recognized as a serious problem. MRSA is endemic in India with the incidence ranging from $30 \%$ to $70 \%$ of all S. aureus infections - the wide range results from differing infection control policies, varied expertise at healthcare facilities, and the type and efficacy of the antibiotics used in different regions.

Table 1: List of few studies reported previously for the skin infections caused by MRSA.

\begin{tabular}{|c|c|c|c|}
\hline Study & Objectives & Study design & Key findings \\
\hline Joshi et al $^{\mathbf{6}}$ & $\begin{array}{l}\text { To evaluate prevalence and } \\
\text { susceptibility pattern of } \\
\text { MRSA in India }\end{array}$ & Survey report & $\begin{array}{l}\text { - Sensitivity to ciprofloxacin was low in both } \\
\text { MSSA }(53 \%) \text { and MRSA }(21 \%) \text {. } \\
\text { - The study showed a high level of MRSA } \\
(41 \%) \text { prevalence }\end{array}$ \\
\hline Nagaraju et al $^{7}$ & $\begin{array}{l}\text { Prevalence of MRSA in } \\
\text { community acquired } \\
\text { pyoderma in south India }\end{array}$ & Prospective study & $\begin{array}{l}\text { - The study showed } 59.7 \% \text { of the patients } \\
\text { with S. aureus nasal colonization } \\
\text { - MSSA strains showed higher resistance } \\
\text { towards commonly used antimicrobials }\end{array}$ \\
\hline Hsiao et $\mathbf{a l}^{8}$ & $\begin{array}{l}\text { Evaluation of role of MRSA } \\
\text { in ocular infection }\end{array}$ & $\begin{array}{l}\text { Retrospective, } \\
\text { observational } \\
\text { study }\end{array}$ & $\begin{array}{l}\text { - } 274 \text { patients identified with MRSA ocular } \\
\text { infections, which comprised 181 CA- } \\
\text { MRSA and 93 HA-MRSA isolates } \\
\text { The annual ratio of CA-MRSA in ocular } \\
\text { MRSA infections averaged } 66.1 \% \text { and } \\
\text { tended to increase over the } 10 \text {-year interval }\end{array}$ \\
\hline Schmitz et al ${ }^{9}$ & $\begin{array}{l}\text { Evaluation of role of TMP- } \\
\text { SMX for uncomplicated skin } \\
\text { abscesses in patients at risk } \\
\text { for community-associated } \\
\text { MRSA infection }\end{array}$ & Clinical trial & $\begin{array}{l}\text { TMP-SMX treatment decreased the formation } \\
\text { of subsequent lesions after uncomplicated } \\
\text { abscess incision. However, it does not reduce } \\
\text { treatment failure. }\end{array}$ \\
\hline
\end{tabular}

MRSA: methicillin-resistant Staphylococcus aureus; S. aureus: Staphylococcus aureus; CA-MRSA: community-acquired MRSA; HAMRSA: hospital-acquired MRSA; TMP-SMX: trimethoprim-sulfamethoxazole.

A large study from 15 Indian tertiary care centres published in 2013 reported the overall prevalence of MRSA as $41 \%$. A more recent study by the Antimicrobial Research And Surveillance Initiative of the Indian Council of Medical Research (ICMR-AMRSN) conducted in four premier institutes in India found the prevalence of MRSA to be $37.3 \%$ (range $21 \%$ to $45 \%$ ). ${ }^{5}$ Various studies of the incidence of MRSA infections in India and globally are detailed in Table 1.

\section{Evolution of MRSA isolates in India}

A rapid increase in the incidence of MRSA is due to the emergence of specific clones with different genotypic characteristics. All the MRSA strains carry the Staphylococcal cassette chromosome mec (SCCmec), but while HA-MRSA strains carry SCCmec types I, II, or III, CA-MRSA have SCCmec IV. Recently a novel staphylococcal cassette chromosome mec (SCCmec) 
element was found in an ST152 methicillin-resistant Staphylococcus aureus (MRSA) and multiple SCCmec types exist in individual MRSA. ${ }^{10,11}$

The majority of HA-MRSA isolates carry SCCmec type III while CA-MRSA mostly belong to ST22 (SCCmec IV), ST772 (SCCmec V), and ST672 (SCCmec V) genotypes. Recently a study had reported the emergence of a more aggressive multidrug resistant MRSA lineages ST2371 and ST8 strains. ${ }^{12}$ CA-MRSA tend to be more virulent than HA-MRSA and often carry genes that encode the Panton-Valentine leucocidin (PVL), as well as many exotoxins that are associated with tissue necrosis and greater severity of disease. ${ }^{13}$ Many variants of epidemic methicillin-resistant Staphylococcus aureus (EMRSA)-15 have been reported over the years. ${ }^{14,15}$

\section{Clinical profile of patients with acute bacterial skin and skin structure infections and importance of MRSA}

Acute bacterial skin and skin structure infections frequently occur in patients with compromised skin integrity, such as maceration, ischemia, immunosuppression, or erosions and wounds that enhance cutaneous colonization. Other factors include trauma, pre-existing skin conditions such as tinea pedis, various chronic skin lesions, and edema due to venous insufficiency. ${ }^{16}$

Table 2: Anti MRSA agents indicated for the treatment for ABSSSI.

\begin{tabular}{|ll|}
\hline Drug & Recommended Dosage \\
\hline Vancomycin & $500 \mathrm{mg}$ q6h or $1 \mathrm{~g}$ q12h IV \\
\hline Teicoplanin & $6 \mathrm{mg} / \mathrm{kg} \mathrm{q} 12 \mathrm{~h}$ IV for 3 doses followed by $6 \mathrm{mg} / \mathrm{kg}$ once daily IV for $7-14$ days \\
\hline Linezolid & $600 \mathrm{mg}$ IV/oral twice daily, for $10-14$ days \\
\hline Daptomycin & $4-6 \mathrm{mg} / \mathrm{kg}$ administered IV every $24 \mathrm{~h}$ for $7-14$ days \\
\hline Tigecycline & $100 \mathrm{mg}$ IV once, then $50 \mathrm{mg}$ IV every $12 \mathrm{~h}$ for $5-14$ days \\
\hline Telavancin & $10 \mathrm{mg} / \mathrm{kg}$ IV every 24 hours for 6 days \\
\hline Ceftaroline & $600 \mathrm{mg}$ every $12 \mathrm{~h}$ for $5-14$ days \\
\hline Clindamycin & $600 \mathrm{mg}$ IV q $8 \mathrm{~h}$ or $300 \mathrm{mg}$ oral q $8 \mathrm{~h}$ \\
\hline TMP-SMX & $1-2 \mathrm{DS}$ tabs twice daily PO \\
\hline Dalbavancin & $1000 \mathrm{mg}$ for 7 days followed by $500 \mathrm{mg}$ \\
\hline Oritavancin & $1200 \mathrm{mg}$ IV single dose \\
\hline Tedizolid & $200 \mathrm{mg}$ IV/oral OD for 6 days \\
\hline
\end{tabular}

ABSSSI: acute bacterial skin and skin structure infection; MRSA: methicillin-resistant $S$. aureus; IV: intravenous.

Table 3: Mechanism of action and limitations of drugs used in the management of MRSA ABSSSI.

\begin{tabular}{|c|c|c|}
\hline Antibiotics & Mechanism of action & Limitations \\
\hline Clindamycin & $\begin{array}{l}\text { Inhibits protein synthesis by } \\
\text { binding to } 50 \text { s ribosomal } \\
\text { subunit }\end{array}$ & $\begin{array}{l}\text { Abdominal pain, diarrhea, nausea, rash, agranulocytosis, } \\
\text { elevated liver enzyme levels, erythema multiforme, jaundice, } \\
\text { pseudomembranous enterocolitis } \\
\text { Inducible resistance can be missed if D-testing not performed } \\
\text { on clinical isolate }\end{array}$ \\
\hline Vancomycin & $\begin{array}{l}\text { Inhibits bacterial cell wall } \\
\text { synthesis }\end{array}$ & $\begin{array}{l}\text { Red man syndrome, nephrotoxicity MIC creep, and potential } \\
\text { for nephrotoxicity at higher concentrations and in combination } \\
\text { with other nephrotoxic agent }\end{array}$ \\
\hline Teicoplanin & Inhibits cell wall synthesis & $\begin{array}{l}\text { Nephrotoxicity, MIC creep, } 2-3 \text { days required to reach } \\
\text { therapeutic levels, even with loading dose, variable tissue } \\
\text { penetration, dose adjustment required in renal patients }\end{array}$ \\
\hline Daptomycin & $\begin{array}{l}\text { Disrupts cell membrane, leading } \\
\text { to rapid depolarization and cell } \\
\text { death }\end{array}$ & $\begin{array}{l}\text { Inactivated by pulmonary surfactant, Skeletal muscle toxicity, } \\
\text { Potential for cross resistance with hVISA, dose adjustment in } \\
\text { renal patients }\end{array}$ \\
\hline Linezolid & $\begin{array}{l}\text { Inhibits protein synthesis at } 50 \mathrm{~S} \\
\text { subunit with prolonged use }\end{array}$ & $\begin{array}{l}\text { Myelosuppression usually related to prolonged therapy }>2 \\
\text { weeks, peripheral neuropathy, serotonin syndrome } \\
\text { Serious side effects like marrow suppression, lactic acidosis } \\
\text { have been reported especially with prolonged use }\end{array}$ \\
\hline Tigecycline & $\begin{array}{l}\text { Inhibits protein synthesis at } 30 \mathrm{~S} \\
\text { subunit }\end{array}$ & $\begin{array}{l}\text { Nausea, vomiting, Low serum levels, Poor tissue penetration, } \\
\text { Black box warning }\end{array}$ \\
\hline
\end{tabular}




\begin{tabular}{|lll|}
\hline $\begin{array}{l}\text { Ceftaroline (fifth- } \\
\text { generation } \\
\text { cephalosporin) }\end{array}$ & $\begin{array}{l}\text { Inhibits bacterial cell wall } \\
\text { synthesis } \\
\text { Used in combination with } \\
\text { daptomycin (synergism) for } \\
\text { salvage therapy }\end{array}$ & $\begin{array}{l}\text { Poor intracellular concentration, dose adjustment in renal } \\
\text { patients, clostridium difficile-associated diarrhoea }\end{array}$ \\
\hline $\begin{array}{l}\text { Telavancin } \\
\text { (lipoglycopeptide) }\end{array}$ & $\begin{array}{l}\text { Inhibits bacterial cell wall } \\
\text { synthesis }\end{array}$ & $\begin{array}{l}\text { Have higher nephrotoxicity rates than vancomycin renal } \\
\text { dysfunction associated with its use, propensity to cause QTc } \\
\text { prolongation, and alteration of laboratory values of } \\
\text { prothrombin time (PT) and activated partial thromboplastin } \\
\text { time (aPTT) }\end{array}$ \\
\hline
\end{tabular}

MIC: minimum inhibitory concentration; PT: prothrombin time; aPTT: activated partial thromboplastin time.

\section{TREATMENT MODALITIES}

\section{Traditional agents for MRSA}

Older drugs used for the treatment of acute bacterial skin and skin structure infections caused by MRSA were clindamycin, trimethoprim-sulfamethoxazole (TMPSMX), doxycycline, and minocycline. The use of clindamycin is limited by its bacteriostatic nature, the high rate of resistance (both inducible and constitutive), as well as a high incidence of Clostridium difficile associated colitis. Tetracyclines and TMP-SMX have limited activity against $S$. aureus. ${ }^{17}$ Vancomycin is the most frequently used antibiotic for the empiric and definitive therapy of systemic MRSA infections as outlined in the Infectious Diseases Society of America (IDSA) treatment guidelines. ${ }^{18}$

\section{Present treatment modalities for MRSA}

Anti-MRSA agents indicated for the treatment for ABSSSI are listed in Table 2.

The mechanism of action and limitations in the treatment of acute bacterial skin and skin structure infections caused by MRSA are elucidated in Table 3.

\section{CHALLENGES IN TREATMENT}

\section{Inappropriate management}

Vancomycin has remained the drug of choice to treat MRSA infections over the past 50 years. The usual dose is $1 \mathrm{~g}$ every $12 \mathrm{~h}$, but this may need to be modified according to the glomerular filtration rate in patients with compromised renal function. Administration may be intermittent based on the susceptibility of strains, but lately the increasing MICs of MRSA strains to vancomycin has led a recent reduction in its usage. ${ }^{19}$ Vancomycin is mildly nephrotoxic and ototoxic when used at conventional dosages but the toxic potential increases at higher dosages especially if other nephrotoxic drugs are used concomitantly. ${ }^{20}$

The clinical practice guidelines published by the Institute of Medicine Committee to advise the Public Health
Service, the Surgical Infection Society, and the World Society of Emergency Surgery recommends empiric antibiotic therapy. The guidelines emphasize the importance of surgical source control. ${ }^{21,22}$

Inappropriate choice of initial antibiotic or treatment duration leads to treatment failure in a large proportion of patients (range: $16.6 \%-34.1 \%$ ) irrespective of source of infection (community or hospital). ${ }^{23}$

Inappropriate categorization of patients with acute bacterial skin and skin structure infections is a major problem in the management of MRSA as antibiotic selection varies with the type and severity of the infection. In wound infections the decision as to whether Gram-positive or Gram-negative bacteria or anaerobes are the cause would clearly alter therapy. The type of discharge may be an important clue, with staphylococcal infections being associated with a purulent discharge while streptococcal infections often produce a watery (non-purulent) discharge. The anatomical location of the wound may also influence management - infections in the perianal area, extensive cellulitis, or rapidly spreading

purulent infections in the neck, hand, face, and genitalia almost always require hospitalization. ${ }^{24}$

\section{Comorbidities}

Comorbidities such as diabetes, cardiovascular disease and stroke, peripheral vascular disease, chronic obstructive pulmonary disease, renal failure, and cancer are commonly associated with MRSA infections and pose an additional challenge in management. ${ }^{7}$ Hospitalized patients with a history of such comorbidities or a prior history of intravenous (IV) drug use, recent surgery, and chronic alcoholism may not only interfere with antibiotic selection ${ }^{25}$ but may elevate the risk of drug interactions (especially when multiple antibiotics are prescribed) and increase the total duration of treatment. ${ }^{26}$

Patients hospitalized with acute bacterial skin and skin structure infections also suffer with diabetes. ${ }^{27}$ Antibiotic treatment in these patients is often prolonged to several weeks and the chances of recurrence are higher. Osteomyelitis as a complication of SSTIs also occurs 
more than twice as frequently in diabetic patients $(13.3 \%)$ as compared to non-diabetics $(5.2 \%){ }^{28}$

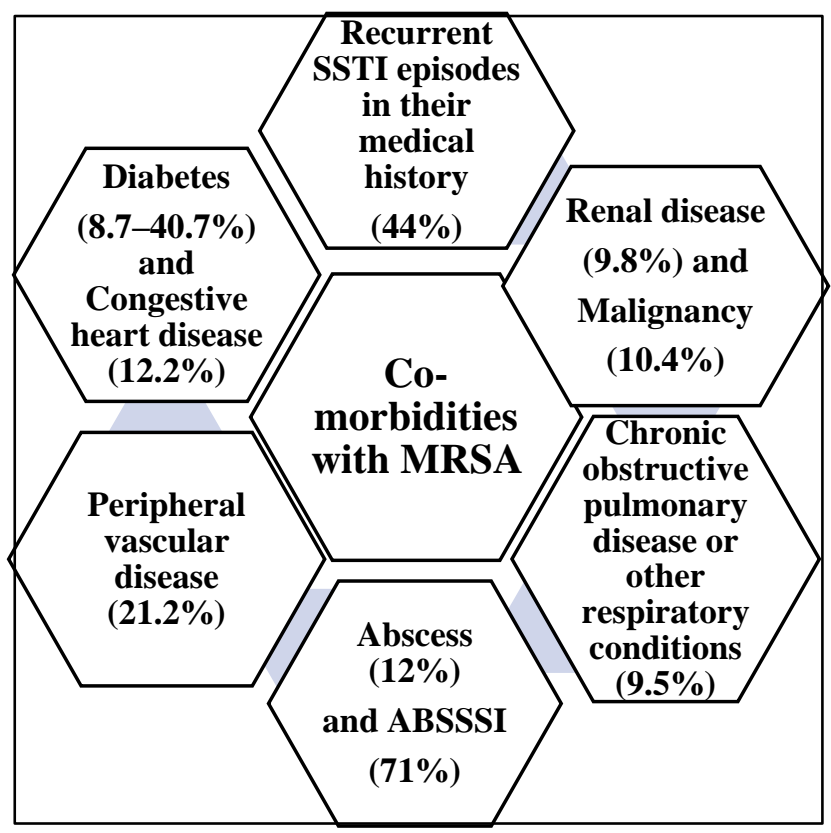

Figure 1: Comorbidities with MRSA ABSSSI.

ABSSSI: acute bacterial skin and skin structure infections, MRSA: methicillin-resistant Staphylococcus aureus, SSTI: skin and soft-tissue infection.

\section{Global financial burden of MRSA}

MRSA infections are responsible for a huge financial burden worldwide. There are few studies of the cost analysis of MRSA infections. Lee et al. used an economic simulation model to estimate that CA-MRSA infections could cost annually an average of $\geq \$ 560$ million to a third party, from $\$ 834,848$ to $\$ 874,797$ to the society and from $\$ 737,618$ to $\$ 780,354$ in direct medical costs..$^{29}$ The CDC estimates that 323,700 hospitalized patients are infected by MRSA annually with at least 10,600 deaths imposing additional costs for US\$ 1.7 billion each year. ${ }^{30}$ Other comparative cost analysis studies have concluded that the economic burden imposed by CA-MRSA is far greater than many other acute infectious diseases with the annual economic burden of CA-MRSA infections being 2-13 times higher than that of pertussis and 8-17 times higher than that of Lyme disease. ${ }^{31,32}$ The overall cost of treatment for acute bacterial skin and skin structure infections with MRSA is high due to the frequent need for hospitalization involving the administration of IV antibiotics and the also the cost of treating the associated comorbidities. The estimated mean cost of an acute bacterial skin and skin structure infections hospitalization in the United States is $\$ 8023$ with a 4.9-day length of stay. ${ }^{3}$

There is a paucity of cost analysis studies in India, but a cross-sectional study conducted in a tertiary healthcare centre estimated the median hospitalization cost for MRSA infection was INR 16,383 and for MSSA it was
INR 11,481 with a median 10 day hospital stay for MRSA and 7.5 days for MSSA infections. Prolonged hospital stay further escalates the treatment costs and morbidity owing to acquisition of nosocomial infections. ${ }^{33}$

\section{NEED OF NEW THERAPIES}

Before the emergence of MRSA, $\beta$-lactam antibiotics were the drugs of choice for skin infections. In 2013, the US FDA redefined acute bacterial skin and skin structure infections and issued recommendations and guidance based on the identification of specific infections. The objective was to rationalize antibiotic choice through quantifiable parameters, such as improvement in the lesion size and systemic signs of infection. ${ }^{34}$

Over the past couple of decades there has been a significant decrease in the development of new antiinfective agents, especially those with a novel mechanism of action. Many derivatives of older antibiotic classes currently used to treat MRSA (Glycopeptides, oxazolidinones, cephalosporins, tetracyclines) and several investigational agents ${ }^{35}$ for treatment of MRSA infections have been in development for several years.

Some newer approaches to enhance the activity of older antibiotics have been explored. Vancomycin-doctaarginine conjugate (V-r8) has been shown to eradicate the MRSA biofilm and persister cells in vitro thus outperforming vancomycin. ${ }^{36}$ Recently, scientists observed that clavulanic acid was highly effective in protecting against beta-lactamase degradation of both penicillin and amoxicillin and found that both cefuroxime and dicloxacillin were highly stable against staphylococcal beta-lactamase degradation. ${ }^{37}$ However, these novel approaches are still under development and long-term effects have not been studied.

A new benzoquinolizine subclass of quinolone derivatives, Levonadifloxacin its oral prodrug, alalevonadifloxacin have been shown to have an established antimicrobial spectrum against clinically significant gram positive and gram negative, atypical, and anaerobic pathogens. The well differentiated mechanism of action primarily towards the DNA gyrase has led to a distinctive potent activity of levonadifloxacin against MRSA, QRSA and hVISA strains. ${ }^{38}$ Moreover, the dual action on DNA gyrase and topoisomerase IV gives levonadifloxacin an added efficacy advantage in topoisomerase IV resistant S.aureus strains. Attractive features such as resistance to NorA efflux pump, effective cidal action against high density cultures, low mutant prevention concentration confers levonadifloxacin with resistance suppression features. Levonadifloxacin has a superior bactericidal action which is observed even in acidic $\mathrm{pH}$, intracellular environment and biofilms thereby retaining its potency and tackling difficult-totreat MRSA infections. ${ }^{39}$ 
Levonadifloxacin also retains a potent antibacterial activity against respiratory pathogens such as macrolideand penicillin -resistant S. pneumonia, S.pyogenes, $H$. influenza and $M$. catarhalis. It provides best in class epithelial lung fluid concentration, thereby promising potential in the treatment of lower respiratory tract infections. ${ }^{40}$ Unlike other anti-MRSA agents, no dosage adjustments are required for levonadifloxacin/ alalevonadifloxacin in renal and hepatic impaired patients. Both the molecules have recently been approved by DCGI (Drug Controller General of India) for the treatment of acute bacterial skin and skin structure infections (ABSSSI), concurrent bacteraemia and diabetic foot infections.

\section{CONCLUSION}

In the recent years, MRSA resistant to multiple antibiotics have become endemic in many countries. However, the FDA approvals of newer antibiotics for treatment of acute bacterial skin and skin structure infections have been on the decline. There is an urgent need not only to develop novel anti-MRSA agents to curb already resistant MRSA strains but also to develop stringent infection control guidelines and strong antibiotic stewardship programs. This approach could help manage MRSA infections with a considerable reduction in morbidity, mortality and hospitalization costs.

\section{Funding: No funding sources}

Conflict of interest: Dr. Jaishid Ahdal and Dr. Rishi Jain are employees of Wockhardt Ltd, Mumbai, India

Ethical approval: Not required

\section{REFERENCES}

1. Esposito S, Bassetti M, Concia E, Simone DG, Rosa FG, Grossi P, et al. Diagnosis and management of skin and soft-tissue infections (SSTI) a literature review and consensus statement: an update. J Chemother. 2017;29(4):197-214.

2. Rodrigues MV, Fortaleza CM, Riboli DF, Rocha RS, Rocha C, Cunha ML, et al. Molecular epidemiology of methicillin - resistant Staphylococcus aureus in a burn unit from Brazil. Burns. 2013;39:1242-9.

3. Pollack CV, Amin A, Ford WT, Finley R, Kaye KS, Nguyen $\mathrm{HH}$, et al. Acute bacterial skin and skin structure infections (ABSSSI): practice guidelines for management and care transitions in the emergency department and hospital. J Emerg Med. 2015;48:508-19.

4. Ray SM. Preventing methicillin-resistant Staphylococcus aureus (MRSA) disease in urban US hospitals now for the hard part: more evidence pointing to the community as the source of MRSA acquisition. J Infect Dis. 2017;215:1631-3.

5. Rajkumar S, Sistla S, Manoharan M, Sugumar M, Nagasundaram N, Parija SC, et al. Prevalence and genetic mechanisms of antimicrobial resistance in Staphylococcus species: a multicentre report of the Indian council of medical research antimicrobial resistance surveillance network. Indian J Med Microbiol. 2017;35:53-60.

6. Joshi S, Ray P, Manchanda V, Bajaj J, Chitnis D, Gautam V, Goswami P, et al. Methicillin resistant Staphylococcus aureus (MRSA) in India: prevalence and susceptibility pattern. Indian J Med Res. 2013;137:363.

7. Nagaraju U, Raju BP. Methicillin-resistant Staphylococcus aureus in community-acquired pyoderma in children in South India. Indian J Paediatr Dermatol. 2017;18:14-7.

8. Hsiao CH, Chuang CC, Tan HY, Ma DH, Lin KK, Chang CJ, et al. Methicillin-resistant Staphylococcus aureus ocular infection: a 10-year hospital-based study. Ophthalmol. 2012;119:522-7.

9. Schmitz GR, Bruner D, Pitotti R, Olderog C, Livengood $\mathrm{T}$, Williams $\mathrm{J}$, et al. Randomized controlled trial of trimethoprim-sulfamethoxazole for uncomplicated skin abscesses in patients at risk for community-associated methicillin-resistant Staphylococcus aureus infection. Ann Emerg Med. 2010;56:283-7.

10. Baig S, Johannesen TB, Petersen S, Larsen J, Larsen AR, Stegger M. Novel SCCmec type XIII (9A) identified in an ST152 methicillin-resistant Staphylococcus aureus. Infect Genetics Evol. 2018:1;61:74-6.

11. Nagasundaram N, Sistla S. Existence of multiple SCCmec elements in clinical isolates of methicillinresistant Staphylococcus aureus. J Med Microbiol. 2019;1768(5):720-7.

12. Bergal A, Loucif L, Benouareth DE, Bentorki AA, Abat C, Rolain JM. Molecular epidemiology and distribution of serotypes, genotypes, and antibiotic resistance genes of Streptococcus agalactiae clinical isolates from guelma, Algeria and Marseille, France. Eur J Clin Microbiol Infect Dis. 2015;34:2339-48.

13. Chua K, Laurent F, Coombs G, Grayson ML, Howden BP. Antimicrobial resistance: Not community- associated methicillin -resistant Staphylococcus aureus (CA-MRSA)! a clinician's guide to community MRSA - its evolving antimicrobial resistance and implications for therapy. Clin Infect Dis. 2011;52:99-114.

14. Boswihi SS, Udo EE, Monecke S, Mathew B, Noronha B, Verghese T, Tappa SB. Emerging variants of methicillin-resistant Staphylococcus aureus genotypes in Kuwait hospitals. PloS one. 2018;13(4):e0195933.

15. Nadig S, Raju SR, Arakere G. Epidemic meticillinresistant Staphylococcus aureus (EMRSA-15) variants detected in healthy and diseased individuals in India. J Med Microbiol. 2010;59(7):815-21.

16. Falcone M, Concia E, Giusti M, Mazzone A, Santini C, Stefani S, et al. Acute bacterial skin and skin 
structure infections in internal medicine wards: Old and new drugs. Intern Emerg Med. 2016;11:637-48.

17. Gould IM, David MZ, Esposito S, Garau J, Lina G, Mazzei T, et al. New insights into meticillinresistant Staphylococcus aureus (MRSA) pathogenesis, treatment and resistance. Int J Antimicrob Agents. 2012;39:96-104.

18. Liu C, Bayer A, Cosgrove SE, Daum RS, Fridkin SK, Gorwitz RJ, et al. Clinical practice guidelines by the Infectious Diseases Society of America for the treatment of methicillin-resistant Staphylococcus aureus infections in adults and children. Clin Infect Dis. 2011;52:18-55.

19. Tee C. MRSA: Challenges and Updates; 2015. Available at https://www.pharmacytimes.com. Accessed on 3 January 2019.

20. Martin JH, Norris R, Barras M, Roberts J, Morris R, Doogue $\mathrm{M}$, et al. Therapeutic monitoring of vancomycin in adult patients: A consensus review of the American Society of Health-System Pharmacists, the Infectious Diseases Society of America, and the Society of Infectious Diseases Pharmacists. Clin Biochem Rev. 2010;31:21-4.

21. Stevens DL, Bisno AL, Chambers HF, Dellinger EP, Goldstein EJ, Gorbach SL, et al. Practice guidelines for the diagnosis and management of skin and soft tissue infections: 2014 update by the Infectious Diseases Society of America. Clin Infect Dis. 2014;59:10-52.

22. Sartelli M, Malangoni MA, May AK, Viale P, Kao LS, Catena F, et al. World Society of Emergency Surgery (WSES) guidelines for management of skin and soft tissue infections. World J Emerg Surg. 2014;9:57.

23. Berger A, Oster G, Edelsberg J, Huang X, Weber DJ. Initial treatment failure in patients with complicated skin and skin structure infections. Surg Infect. 2013;14:304-12.

24. Rodríguez MC, Castro AV, Ledo VL, Veleiro NI, Quintela GA. Skin and soft-tissue infections: Factors associated with mortality and re-admissions. Enferm Infect Microbiol Clin. 2017;35:76-81.

25. Mcginnis E, Cammarata S, Tan RD, Barrett M, Tuttle E. Characteristics of patients hospitalized for acute bacterial skin and skin structure infections (ABSSSI) from 2009 to 2013. Open Forum Infect Dis. 2016;3(1):279.

26. Dryden M, Andrasevic AT, Bassetti M, Bouza E, Chastre J, Cornaglia G, et al. A European survey of antibiotic management of methicillin-resistant Staphylococcus aureus infection: Current clinical opinion and practice. Clin Microbiol Infect. 2010;16(1):3-10.

27. Dryden M, Baguneid M, Eckmann C, Corman S, Stephens J, Solem C, et al. Pathophysiology and burden of infection in patients with diabetes mellitus and peripheral vascular disease: Focus on skin and soft-tissue infections. Clin Microbiol Infect. $2015 ; 21(2): 27-32$.
28. Suaya JA, Eisenberg DF, Fang C, Miller LG. Skin and soft tissue infections and associated complications among commercially insured patients aged 0-64 years with and without diabetes in the U.S. PLoS One. 2013;8:60057.

29. Lee BY, Singh A, David MZ, Bartsch SM, Slayton RB, Huang SS, et al. The economic burden of community- associated methicillin-resistant Staphylococcus aureus (CA - MRSA). Clin Microbiol Infect. 2013;19:528-36.

30. Methicillin resistant Staphylococcus aureus. Available at https://www.cdc.gov. Accessed on 26 December 2019.

31. Scharff RL. Health-related costs from foodborne illness in the United States; 2010. Available at https://www.pewtrusts.org. Accessed on 1 October 2019.

32. Labreche MJ, Lee GC, Attridge RT, Mortensen EM, Koeller J, Du LC, et al. Treatment failure and costs in patients with methicillin-resistant Staphylococcus aureus (MRSA) skin and soft tissue infections: A South Texas ambulatory research network (STARNet) study. J Am Board Fam Med. 2013;26:508-17.

33. US Food and Drug Administration. Center for drug evaluation and research. guidance for industry. acute bacterial skin and skin structure infections: Developing drugs for treatment. Draft Guidance. Clinical/antimicrobial revision. Food and Drug Administration, Center for Drug Evaluation and Research; 2010. Available at http://www.fda.gov/download. Accessed on 21 December 2018.

34. Moellering RC. Discovering new antimicrobial agents. Int J Antimicrob Agents. 2011;37:2-9.

35. Vuong $\mathrm{C}$, Yeh AJ, Cheung GY, Otto $\mathrm{M}$. Investigational drugs to treat methicillin-resistant Staphylococcus aureus. Expert Opin Investig Drugs. 2016;25:73-93.

36. Antonoplis A, Zang X, Huttner MA, Chong KK, Lee YB, Co JY, et al. A dual-function antibiotictransporter conjugate exhibits superior activity in sterilizing MRSA biofilms and killing persister cells. J Am Chem Soc. 2018;140:16140-51.

37. Skov RO, Frimodt MNI, Espersen FR. In vitro susceptibility of Staphylococcus aureus towards amoxycillin-clavulanic acid, penicillin-clavulanic acid, dicloxacillin and cefuroxime. Apmis. 2002;110(7-8):559-64.

38. Bhagwat SS, Nandanwar M, Kansagara A, Patel A, Takalkar S. Levonadifloxacin, a novel broadspectrum anti-mrsa benzoquinolizine quinolone agent: review of current evidence. Drug Des Devel Ther. 2019;13:4351-65.

39. Tellis M, Joseph J, Khande H, Bhagwat S, Patel M. In vitro bactericidal activity of levonadifloxacin (WCK 771) against methicillin-and quinoloneresistant Staphylococcus aureus biofilms. J Med Microbiol. 2019;26:1-8. 
40. Rodvold KA, Gotfried MH, Chugh R. Intrapulmonary pharmacokinetics of levonadifloxacin following oral administration of alalevonadifloxacin to healthy adult subjects. Antimicrob Agents Chemother. 2018;62(3):0229717.
Cite this article as: Mahakalkar C, Padhye D, Nandagawali VR, Takale S, Ahdal J, Jain R. Management of acute bacterial skin and skin structure infections in India: are we equipped to meet the challenges of the growing menace of methicillinresistant Staphylococcus aureus? Int Surg J 2020;7:3172-9. 